\title{
Association between RBMS1 gene rs7593730 and BCAR1 gene rs7202877 and Type 2 diabetes mellitus in the Chinese Han population
}

\author{
Elena V. Kazakova1, Meijun Chen'1 , Esma Jamaspishvili ${ }^{1}$, Zhang Lin, Jingling $\mathrm{Yu}^{2}$, Lulu Sun ${ }^{1}$ \\ and Hong Qiao ${ }^{\bowtie}$
}

'Department of Endocrinology and Metabolism, the Second Affiliated Hospital, Harbin Medical University, Harbin, Heilongjiang, China; ${ }^{2}$ General Hospital of Jixi Mining Group, Jixi, Heilongjiang, China

Two recent studies found that RBMS1 gene rs7593730 and BCAR1 gene rs7202877 are related to type 2 diabetes. However, the association of these loci with type 2 diabetes mellitus (T2DM) has not been examined in Chinese. We performed a replication study to investigate the association of the 2 susceptibility loci with T2DM in the Chinese population. We genotyped 1961 Chinese participants (991 with T2DM and 970 controls) for each of the 2 single nucleotide polymorphisms (SNPs) rs7593730 in RBMS1 and rs7202877 near BCAR1 using SNPscan and examined their association with T2DM using logistic regression analysis. We also analyzed the correlation of the SNP alleles and clinical phenotypes. In additive model, genotype association analysis of BCAR1 rs7202877 loci revealed that the homozygous of rs7202877 GG carriers had significantly decreased T2DM risk compared to homozygous carriers of TT $(P=0.038$, OR $0.44,95 \% \mathrm{Cl} 0.20-0.96)$. In the recessive model, the GG genotype GG had significantly decreased T2DM risk compared to GT+TT ( $P=0.043$, OR $0.67,95 \%$ $\mathrm{Cl} 0.46-0.99)$. Allele $\mathrm{G}$ was statistically significantly correlated with TC $(\mathrm{mmol} / \mathrm{L})(P=0.036)$ and $\mathrm{LDL}-\mathrm{C}(\mathrm{mmol} / \mathrm{L})$ $(P=0.007)$. As for rs7593730, the carriers of $C T$ and TT genotype had significantly decreased T2DM risk compared to the carriers of CC genotype (CT: CC $P=0.038$, OR $0.71,95 \%$ Cl $0.51-0.98$; TT: CC $P=0.010$, OR $0.32,95 \%$ Cl 0.13-0.76). In a dominant model, TT+CT: CC ( $P=0.013$, OR $0.673,95 \% \mathrm{Cl} 0.49-0.92$ ) and in a recessive model, TT: $C T+C C(P=0.019$, OR $0.59,95 \% \mathrm{Cl} 0.39-0.92)$. The $\mathrm{T}$ allele carriers had significantly decreased T2DM risk compared to the carriers of $C(P=0.002$, OR $0.65,95 \% \mathrm{Cl}$ $0.50-0.86)$. Allele $T$ was statistically correlated with FINS $(P=0.010)$. In conclusion, our study showed that RBMS1 gene rs7593730 and BCAR1 gene rs7202877 were significantly associated with type 2 diabetes in the Chinese population.

Key words: type 2 diabetes mellitus, RBMS1 gene, BCAR1 gene, single nucleotide polymorphisms, SNPscan

Received: 08 November, 2016; revised: 11 December, 2017; accepted: 09 June, 2018; available on-line: 08 September, 2018

e-mail: qiaoh0823@sina.com

Abbreviations: BCAR1, breast cancer anti-estrogen resistance $1_{i}$ CAS, Crk-associated substrate protein; GWAS, genome-wide association studies; T2DM, type 2 diabetes mellitus; RBMS1, RNA binding motif single stranded interacting protein 1; SNP, single nucleotide polymorphism

\section{INTRODUCTION}

Type 2 diabetes mellitus (T2DM) is the most common type of diabetes mellitus, which is characterized by insulin resistance combined with relatively reduced insulin secretion (Chehade \& Mooradian, 2000; DeFronzo et al., 2004; Wild et al., 2004; Carpino \& Goodwin, 2010). It is a chronic metabolic disease that affects the body's ability to turn food into energy. People developing T2DM may suffer from blindness, renal failure, coronary artery disease, and so forth. Because of its dramatic increase worldwide, T2DM has reached an epidemic scale that is anticipated to affect over 360 million people by 2030 . The prevalence of type 2 diabetes in adults has increased to $9.7 \%$ in China (Pan et al., 2009; Yang et al., 2010; Tao et al., 2016).

Recently, studies of gene polymorphism are more and more popular, which helped to find new genes associated with T2DM susceptibility. More than 75 T2DM susceptibility-related genes have been identified so far, mostly through genome-wide association studies (GWAS) (Sanghera \& Blackett, 2012). These novel findings offer unique insight into the pathogenesis of T2DM development and function (McCarthy \& Zeggini, 2009).

Previous studies reported that two identified genes were directly or indirectly in correlation with T2DM. RNA binding motif single stranded interacting protein 1 (RBMS1) gene is located on the human chromosome 2q24.2. RBMS1 gene encodes a member of a small family of proteins that binds single-stranded DNA/RNA and is implicated in diverse functions such as DNA replication, gene transcription, apoptosis and cell cycle progression by interacting with the c-Myc protein (Takai et al., 1994). The RBMS1 is expressed in many T2DM-related tissues such as muscle, liver and adipose tissue (Qi et al., 2010; Zhu et al., 2015). However, the role of this gene in diabetogenic pathways has not been reported.

The allele $\mathrm{T}$ of the single nucleotide polymorphism (SNP) rs7593730 was associated with a $0.009 \mathrm{mmol} / \mathrm{L}$ lower fasting glucose $(P=4.35 \mathrm{E}-2)$ in the Meta-Analysis of Glucose and Insulin-related traits Consortium (Qi et al., 2010). It was indicated that another SNP rs6718526 in RBMS1 is associated with the risk of T2DM in Antioquian, a South American mestizo population (Campbell et al., 2012).

Breast cancer anti-estrogen resistance 1 (BCAR1), also named p130cas, is one of the Crk-associated substrate protein (CAS) family members (Reynolds et al., 1989; 
Kanner et al., 1991). As an adapter protein, BCAR1 localizes to chromosome 16q22-q233. BCAR1 has important roles in a variety of cellular processes, such as apoptosis, cell cycle, migration, chemotaxis, and differentiation (Cabodi et al., 2006; Tang, 2009; Cabodi et al., 2010; Tikhmyanova et al., 2010).

Three articles reported that BCAR1 gene rs7202877 was associated with T2DM. A genome-wide association study in European American and African Americans identified rs7202877 as a susceptible locus for T2DM (Keaton et al., 2014). Recently, Marie N. Harder and other scholars found in Danish individuals that BCAR1 rs7202877 may mediate its diabetogenic impact through impaired B-cell function (Harder et al., 2013). However, analysis performed on Japanese subjects could not confirm the association of BCAR1 locus with T2DM risk (Matsuba et al., 2015).

To improve our understanding of the role of RBMS1 and BCAR1 genes in T2DM predisposition, it is extremely important to understand the consequences of genetic diversity in other ethnic populations. Han Chinese constitutes the largest ethnic group in the world, and its spurious associations due to the population structure pose a challenge to genetic studies. The role of RBMS1 and BCAR1 genes in T2DM in the Han population has not been referred in the literature. Therefore, we conducted a case-control study to investigate the role of RBMS1 and BCAR1 genes SNPs in T2DM risk in the Han population in northeastern China by SNPscan method.

\section{MATERIALS AND METHODS}

Study population and clinical parameters. All subjects were recruited from the outpatient clinics of the Second Affiliated Hospital of Harbin Medical University, including 991 T2DM patients and 970 controls. The patients had given consent to take part in the research and the Authors have a document stating that ethical issues had been considered (this fact sheet has been endorsed by the University Research Ethics Committee). The patients were of the Han Chinese residing in the northeast area.

The inclusion criteria for the control group were the following: 1) HbA1c $<6.0 \%$; 2) Fasting Plasma Glucose (FPG) $<5.1 \mathrm{mmol} / \mathrm{L}$; 3) no history of diagnosing diabetes; 4) no family history of T2DM; 5) no treatment with drugs that affect lipid and carbohydrate exchange; 6) no systemic diseases.

T2DM was diagnosed by the criteria of the World Health Organization (WHO) from 1999 (Alberti \& Zimmet, 1998), as the following features: FPG $\geq 7.0 \mathrm{mmol} / \mathrm{L}$ and/or 2 hours postprandial plasma glucose $\geq 11.1$ $\mathrm{mmol} / \mathrm{L}$. In this group, diabetes was diagnosed not more than six months earlier, and the subjects were not treated with insulin.

Exclusion criteria for the study group were: 1) renal and hepatic failure; 2) cardiovascular disease; 3) acute diabetic complications; 4) malignant tumors, severe injury, infections, and endocrine diseases; 5) other types of diabetes; 6) type 2 diabetes patients receiving the lipid-lowering and/or oral hypoglycemic agents were not included in the study group.

Firstly, gender, age, height, weight, waist circumference, hip circumference, and blood pressure were recorded. Secondly, the clinical parameters of patients were tested, including FPG, total cholesterol (TC), triacylglycerol (TG), high density lipoprotein cholesterol
(HDL-C), low density lipoprotein cholesterol (LDL-C), fasting insulin (FINS) concentration and HbA1c. Finally, waist-hip ratio (WHR), homeostasis model of assessment for insulin resistance index (HOMA-IR) and body mass index (BMI) were calculated.

DNA extraction and genotype analysis. About 4-ml samples of venous blood were collected from each person. Blood samples were collected from patients using Vacutainers and transferred to tubes lined with ethylene diamine tetraacetic acid (EDTA). SNP genotyping was performed using a custom-made $2 \times 48$-Plex SNPscan ${ }^{\mathrm{TM}}$ Kit (cat. no. G0104; Genesky Biotechnologies Inc., Shanghai, China). The kit was developed according to patented SNP genotyping technology by Genesky Biotechnologies Inc., which was based on double ligation and multiplex fluorescence PCR. In order to validate the genotyping accuracy using SNPscan ${ }^{\mathrm{TM}} \mathrm{Kit}$, a $5 \%$ random sample of cases and controls were genotyped twice per all SNPs by different persons. In detail, we included 100 pairs of blind duplicates and the concordance rates were more than $98 \%$.

Statistical analyses. The Hardy-Weinberg equilibrium was evaluated using Pearson's $\chi^{2}$ test separately for cases and controls. Differences between cases and controls in demographic characteristics and risk factors were evaluated by $\chi^{2}$ test (for categorical variables) or Student's $t$-test (for continuous variables). The allele frequencies between cases and controls were compared using $\chi^{2}$ test. Statistical evaluations for testing the genetic effects of association between the case-control status and each individual SNP, measured by the odds ratios (ORs) and 95\% confidence intervals (CIs), were estimated using unconditional logistic regression after adjusting for gender, age, WHR, TG, HDL-C, HOMA-IR. Correlation between variables and each SNP allele was determined using Spearman's correlation test. SPSS 17.0 software package (SPSS, Chicago, Illinois, USA; version 13.0) was used for all statistical analyses. All presented $P$ values were two-sided, and the level of $P<0.05$ was considered statistically significant.

\section{RESULTS}

\section{Characteristics of the study population}

Characteristics of the cases and controls were shown in Table 1. 991 T2DM patients and 970 nondiabetic controls were genotyped for SNPs (RBMS1 - rs7593730 and BCAR1 - rs7202877) and analyzed for association with T2DM. The differences in the distribution of gen$\operatorname{der}(P=0.191)$ and LDL-C $(P=0.787)$ between cases and controls were not statistically significant. The differences of the other clinical parameters between cases and controls were statistically significant, including age, WHR, FPG, HbA1c, FINS, TC, TG, HDL-C and HOMA-IR.

\section{Analysis of SNP rs7202877 and rs7593730 association with T2DM}

Genotype distribution of the investigated SNPs did not deviate from Hardy-Weinberg equilibrium both in cases and controls. The genotype distribution of RBMS1 rs7593730 and BCAR1 rs7202877 in the cases and the controls was shown in Table 2. T2DM group did not include any type 2 diabetes patients receiving the lipidlowering and/or oral hypoglycemic agents. It was one of the inclusion conditions in this study. In the homozygote model, genotype association analysis of BCAR1 
Table 1. Clinical characteristic of the study participants.

\begin{tabular}{lccc}
\hline Variables & Case $(\mathrm{n}=991)$ & Control $(\mathrm{n}=970)$ & $P$ \\
\hline Gender(male:female) & $609: 382$ & $568: 402$ & 0.191 \\
\hline Age (years) & $46.10 \pm 12.58$ & $42.88 \pm 11.67$ & $<0.001$ \\
\hline WHR & $0.94 \pm 0.06$ & $0.85 \pm 0.07$ & $<0.001$ \\
\hline FPG & $10.03 \pm 3.41$ & $4.84 \pm 0.29$ & $<0.001$ \\
\hline HbA1C & $9.29 \pm 2.36$ & $5.12 \pm 0.47$ & $<0.001$ \\
\hline FINS & $12.89 \pm 7.60$ & $7.86 \pm 4.42$ & $<0.001$ \\
\hline TC (mmol l-1) & $5.00 \pm 1.29$ & $4.88 \pm 1.05$ & 0.039 \\
\hline TG (mmol l-1) & $2.38 \pm 2.24$ & $1.43 \pm 0.96$ & $<0.001$ \\
\hline HDL-C (mmol I-1) & $1.21 \pm 0.32$ & $1.48 \pm 0.37$ & $<0.001$ \\
\hline LDL-C (mmol l-1) & $2.91 \pm 0.96$ & $2.92 \pm 0.87$ & 0.787 \\
\hline HOMA-IR & $5.76 \pm 4.05$ & $1.69 \pm 0.97$ & $<0.001$ \\
\hline
\end{tabular}

WHR, waist-hip ratio; FPG, Fasting plasma glucose; FINS, fasting insulin; TC, total cholesterol; TG, triacylglycerol; HDL-C, high density lipoprotein cholesterol; LDL-C, low density lipoprotein cholesterol; HOMA-IR, homeostasis model of assessment for insulin resistance index. Data are shown as means \pm S.D.

Table 2. The genotype distributions and the effect on the risk of type 2 diabetes.

\begin{tabular}{|c|c|c|c|c|c|c|c|c|}
\hline Gene & SNP & Genotype & Case & Control & $P$ & $\mathrm{OR}(95 \% \mathrm{Cl})$ & $P^{*}$ & $\mathrm{OR}^{*}(95 \% \mathrm{Cl})$ \\
\hline \multirow[t]{5}{*}{ BCAR1 } & rs7202877 & $\pi$ & 635 & 613 & NA & 1 & NA & 1 \\
\hline & & GT & 317 & 314 & 0.792 & $0.98(0.81-1.18)$ & 0.634 & $0.93(0.68-1.26)$ \\
\hline & & GG & 39 & 43 & 0.560 & $0.88(0.56-1.37)$ & 0.038 & $0.44(0.20-0.96)$ \\
\hline & & Dominant & & & 0.734 & $0.97(0.81-1.16)$ & 0.363 & $0.87(0.65-1.17)$ \\
\hline & & Recessive & & & 0.586 & $0.94(0.75-1.17)$ & 0.043 & $0.67(0.46-0.99)$ \\
\hline \multirow[t]{5}{*}{ RBMS1 } & rs7593730 & $\mathrm{CC}$ & 682 & 657 & NA & 1 & NA & 1 \\
\hline & & $\mathrm{CT}$ & 285 & 276 & 0.958 & $1.00(0.82-1.21)$ & 0.038 & $0.71(0.51-0.98)$ \\
\hline & & $\pi$ & 24 & 37 & 0.079 & $0.63\left(0.37-1.06^{*}\right.$ & 0.010 & $0.32(0.13-0.76)$ \\
\hline & & Dominant & & & 0.722 & $0.97(0.80-1.17)$ & 0.013 & $0.67(0.49-0.92)$ \\
\hline & & Recessive & & & 0.061 & $0.78(0.60-1.01)$ & 0.019 & $0.59(0.39-0.92)$ \\
\hline
\end{tabular}

$P$ value adjusted for gender, age, WHR, TG, HDL-C, HOMA-IR

Table 3. Allele association analysis of the SNPs with type 2 diabetes.

\begin{tabular}{llcccc}
\hline SNP & allele & $P$ & OR $(95 \% \mathrm{Cl})$ & $P^{*}$ & $\mathrm{OR}^{*}(95 \% \mathrm{Cl})$ \\
\hline rs7202877 & $\mathrm{G} / \mathrm{T}$ & 0.591 & $0.96(0.82-1.12)$ & 0.120 & $0.82(0.63-1.05)$ \\
\hline rs7593730 & $\mathrm{T} / \mathrm{C}$ & 0.306 & $0.92(0.78-1.08)$ & 0.002 & $0.65(0.50-0.86)$ \\
\hline
\end{tabular}

" $P$ value adjusted for gender, age, WHR, TG, HDL-C, HOMA-IR

rs7202877 loci revealed that the homozygous GG carriers had significantly decreased T2DM risk compared to homozygous carriers of TT $(P=0.038$, OR $0.44,95 \%$ CI $0.20-0.96$ ) after adjustments for gender, age, waist-hip ratio, triglyceride, HDL-C, HOMA-IR. In the recessive model, it was shown that the genotype GG carriers had significantly decreased T2DM risk compared to GT+T'T $(P=0.043$, OR $0.67,95 \%$ CI $0.46-0.99)$.

We further analyzed the effect of the genotype of RBMS1 rs7593730 under genetic model by logistic tests. The carriers of CT and T'T genotypes had significantly decreased T2DM risk compared to the carriers of CC genotype (CT: CC $P=0.038$, OR $0.71,95 \%$ CI 0.51-0.98; TT: CC $P=0.010$, OR $0.32,95 \%$ CI $0.13-0.76)$. In the dominant model, TT+CT: CC $(P=0.013$, OR 0.673, 95\% CI 0.49-0.92) and in the recessive model, TT: CT+CC $(P=0.019$, OR 0.59, 95\% CI 0.39-0.92).

Allele association analysis of rs7593730 and rs7202877 with type 2 diabetes was showed in Table 3. In rs7593730, the $\mathrm{T}$ allele carriers had significantly decreased T2DM risk compared to carriers of $\mathrm{C}(P=0.002$, OR $0.65,95 \%$ CI $0.50-0.86)$ after adjustments for gender, age, WHR, TG, HDL-C, HOMA-IR.

\section{Correlation analysis between clinical parameters and the two SNPs}

The SNP rs7202877 allele G (Table 4) was statistically significantly correlated with TC $(\mathrm{mmol} / \mathrm{L})(P=0.036)$ and 
Table 4. Correlations between the SNPs and clinical parameters.

\begin{tabular}{|c|c|c|c|c|c|c|c|c|c|c|}
\hline SNP & Allele & & FPG & $\mathrm{TC}$ & TG & $\mathrm{HDL}-\mathrm{C}$ & LDL-C & FINS & $\mathrm{HbA1c}$ & Homa-IR \\
\hline \multirow[t]{2}{*}{ rs7202877 } & G & $r$ & -0.003 & $0.034^{*}$ & -0.005 & 0.029 & $0.043^{* *}$ & 0.001 & -0.004 & -0.001 \\
\hline & & $p$ & 0.867 & 0.036 & 0.774 & 0.068 & 0.007 & 0.961 & 0.786 & 0.928 \\
\hline \multirow[t]{2}{*}{ rs7593730 } & $\mathrm{T}$ & $r$ & -0.006 & -0.011 & 0.007 & -0.011 & 0.007 & $0.041^{*}$ & -0.020 & 0.024 \\
\hline & & $p$ & 0.715 & 0.507 & 0.640 & 0.507 & 0.648 & 0.010 & 0.218 & 0.135 \\
\hline
\end{tabular}

r. Pearson correlation coefficient. ${ }^{*} P$-value (Double) 0.01 , correlation is significant. ${ }^{*} P$-value (Double) 0.05 , correlation is significant.

LDL-C (mmol/L) $(P=0.007)$. The SNP rs7593730 allele $\mathrm{T}$ was statistically correlated with FINS $(P=0.010)$.

\section{DISCUSSION}

In 2012, an European GWAS meta-analysis identified rs7202877 near BCAR1 as associated with type 2 diabetes (Morris et al., 2012). A study from Harvard University showed that the $\mathrm{T}$ allele of rs7593730 was associated with a $10 \%$ lower odds of T2DM (Qi et al., 2010). It is well known that the frequencies and the effects of genetic variations are different among ethnic groups and geographic regions. As we all know, the prevalence of diabetes is high and is increasing fast in China ( $\mathrm{Zhu}$ et al., 2015). Therefore, investigating the two SNPs associated with the risk of type 2 diabetes in China is especially important. In this case-control study, we sought to evaluate the association of two SNPs, rs7593730 in RBMS1 and rs7202877 near BCAR1, with susceptibility to type 2 diabetes in the Chinese Han population.

We analyzed the effect of the genotype of RBMS1 rs7593730 under genetic model by logistic tests. In the additive model, the genotype $\mathrm{CT}$ and $\mathrm{T} T$ reduced the risk of T2DM compared to CC (CT: CC P=0.038, OR $0.71,95 \%$ CI $0.51-0.98$; TT: CC $P=0.010$, OR 0.32 , $95 \%$ CI 0.13-0.76). The allele $\mathrm{T}$ was associated with significantly decreased T2DM risk compared to allele C $(P=0.002$, OR $0.65,95 \%$ CI $0.50-0.86)$, which was similar to the previous study that $\mathrm{T}$ was the protective allele $\left(P=3.7 \times 10^{-8}\right.$, OR 0.90 , 95\% CI 0.86-0.93) (Qi et al., 2010). Correlation analysis showed that the SNP rs7593730 allele $T$ was statistically correlated with FINS $(P=0.010)$. This result was also consistent with the findings of the previous study that allele $\mathrm{T}$ of rs7593730 was associated with a $0.009 \mathrm{mmol} / \mathrm{L}$ lower fasting glucose (=4.35E-2) (Qi et al., 2010). We infer that rs7593730 is likely related to T2DM via influencing insulin secretion.

The association of another SNP rs6718526 in RBMS1 was defined in Antioquian, a South American mestizo population GWAS (Campbell et al., 2012). It was shown that logistic regression incorporating SES, BMI and ancestry as covariates found nominally significant association $(P<0.05)$ for rs6718526 (RBMS1) (Campbell et al., 2012). The molecular pathogenesis by which RBMS1 gene participates in T2DM is not yet clear. Qi with others demonstrated that RBMS1 is expressed in tissues of biological relevance to T2DM such as muscle, liver and adipose tissue (Qi et al., 2010). RBMS1 also appeared responsive to inflammation, as demonstrated in vitro when cells were directly exposed to inflammatory agents and in vivo. Since inflammation is implicated in T2DM (Shoelson et al., 2006), it is possible that the association between variants encompassing RBMS1 with T2DM is mediated through a role in inflammatory pathways. In addition, a high-fat diet tended to induce the expression of RBMS1 (Qi et al., 2010). Furthermore, rs7593730 was confirmed to have cis-regulation effects on the expression of RBMS1 gene, and the RBMS1 was proved to have differential expression signals in the T2DM-associated cell groups (Zhu et al., 2015). We are fully aware of the exploratory nature of these experiments and more extensive follow-up is required before proposing such a mechanism.

Genotype association analysis of BCAR1 rs 7202877 locus in our study revealed that the homozygous GG carriers had significantly decreased T2DM risk compared to homozygous carriers of T'T $(P=0.038$, OR $0.44,95 \%$ CI $0.20-0.96$ ). In the recessive model, it was shown that the GG genotype carriers had significantly decreased T2DM risk compared to $\mathrm{GT}+\mathrm{TT}(P=0.043$, OR 0.67 , 95\% CI $0.46-0.99)$. The results were similar to the previous European GWAS study that $G$ was the protective allele (Morris et al., 2012). A genome-wide association (GWA) study in European American and African Americans also identified rs7202877 as a susceptible locus for T2DM (Keaton et al., 2014). Leen M. 't Hart reported the positive effects of the $G$ allele of rs7202877 on GLP-1-stimulated insulin secretion; subjects carrying the $G$ allele showed a 33\%-increase in GLP-1-stimulated insulin secretion $\left(P=1.9 \times 10^{-6}\right)$, which likely explained the protective effect of this allele on type 2 diabetes susceptibility ("t Hart et al., 2013). Recently, Marie N. Harder and other scholars found in Danish population that $\mathrm{T}$ allele of BCAR1 rs7202877 had increased 30-minute and 2-hour glucose levels, suggesting that the $\mathrm{T}$ allele may confer T2D risk through impairment of B-cell function (Harder et al., 2013). However, the Japanese GWAS showed BCAR1 gene SNP rs7202877 could not replicate the association with future risk of T2DM (Keaton et al., 2014). Frequencies of some genetic variations may be different among ethnic groups and geographic regions. The effects of this SNP locus need to be evaluated in sufficiently powered, larger populations.

We also found that the allele $G$ of rs7202877 was statistically correlated with TC (mmol/L) $(P=0.036)$ and LDL-C $(\mathrm{mmol} / \mathrm{L})(P=0.007)$. It is known that in diabetes the postprandial regulation of lipids is impaired as a result of insulin resistance and inadequate secretion of insulin, leading to increased levels of triglycerides and cholesterol (Laakso et al., 1993; Alberti et al., 2006). Insulin also promotes the synthesis of lipids, and inhibits their degradation (Saltiel \& Kahn, 2001). It is known that plasma cholesterol levels are independently associated with insulin resistance and are independent predictors of CVD (Manninen et al., 1992). BCAR1 also plays a critical role inside the beta cells and was naturally linked with various insulin-related conditions, not only T2DM, but also other diseases and symptoms such as obesity and atherosclerosis. Sweden scholars found that 
the BCAR1-CFDP1-TMEM170A is implicated in atherosclerotic cardiovascular disease and chronic obstructive pulmonary disease, which both have strong inflammatory components and involve tissue remodeling, including dysregulation of smooth muscle cell phenotype and function, and which exhibit pronounced comorbidity (Maclay et al., 2007; Gertow et al., 2012).

An association does not necessarily mean that the nucleotide change at the associated SNP leads to direct effects on the phenotype under study. Therefore, it is likely that some causal variants could be ethnic-specific or could be present elsewhere in the same or nearby gene. It was suggested that differences in the pattern of linkage disequilibrium between these SNPs and functional variants at these loci could underlie these disparate findings. Alternatively, gene-environment interactions may operate in the pathogenesis of T2DM and those differences in the level of environmental risk factors in various populations may alter the impact of susceptibility loci on the risk of T2DM.

In the current samples, comprised of the Han population in northeastern China, false-positive or false-negative associations owing to population substructure are less likely to exist. The population was relatively homogeneous: the subjects all lived in the same area with sharp-continental climate, had the same dietary preferences in the ratio of fat and carbohydrates and belonged to the same ethnic group. To our knowledge, this study is the first to demonstrate that the RBMS1 gene rs7593730 and BCAR1 gene rs7202877 are associated with T2DM in the northeastern Han Chinese.

However, several inherent limitations must be noted. As the controls were recruited from hospitals, some level of selection bias could not be ruled out. All control individuals in our study came to the hospitals for routine health examination, not hospitalized as a result of specific diseases. This probably made the controls more representative of the general population. Under existing conditions, the potential selection bias was believed to be minimized.

\section{CONCLUSION}

We observed significant association of RBMS1 gene rs7593730 and BCAR1 gene rs7202877 with type 2 diabetes in the Chinese population. The results indicate that they are common type 2 diabetes susceptibility loci across different ethnic groups. However, further functional studies are necessary to elucidate the biological mechanisms of each locus for conferring susceptibility to the disease.

\section{Conflict of interest statement}

The authors declare that there are no conflicts of interest..

\section{Acknowledgements}

We gratefully acknowledge the numerous sample donors for making this work possible.

\section{Acknowledgements of Financial Support}

This work was funded by the National Natural Science Foundation of China (81473053), the Natural Science Foundation of Heilongjiang Province (ZD201220), National Basic Research Program of China (SQ2013CB051164). The funders had no role in study design, data collection and analysis, decision on publication, or preparation of the manuscript.

\section{REFERENCE}

Alberti KG, Zimmet P, Shaw J (2006) Metabolic syndrome - a new world-wide definition. A Consensus Statement from the International Diabetes Federation. Diabetic Med: J Brit Diabetic Ass 23: 469480. https://doi.org/10.1111/j.1464-5491.2006.01858.x

Alberti KG, Zimmet PZ (1998) Definition, diagnosis and classification of diabetes mellitus and its complications. Part 1: diagnosis and classification of diabetes mellitus provisional report of a WHO consultation. Diabetic Med: J Brit Diabetic Ass 15: 539-553. https:// doi.org/10.1002/(SICI)1096-9136(199807)15:7\%3C539::AIDDIA668\%3E3.0.CO;2-S

Cabodi S, Tinnirello A, Bisaro B, Tornillo G, del Pilar Camacho-Leal M, Forni G, Cojoca R, Iezzi M, Amici A, Montani M, Eva A, Di Stefano P, Muthuswamy SK, Tarone G, Turco E, Defilippi P (2010) p130Cas is an essential transducer element in ErbB2 transformation. FASEB J 24: 3796-380. https://doi.org/10.1096/fj.10-157347

Cabodi S, Tinnirello A, Di Stefano P, Bisaro B, Ambrosino E, Castellano I, Sapino A, Arisio R, Cavallo F, Forni G, Glukhova M, Silengo L, Altruda F, Turco E, Tarone G, Defilippi P (2006) p130Cas as a new regulator of mammary epithelial cell proliferation, survival, and HER2-neu oncogene-dependent breast tumorigenesis. Cancer Res 66: 4672-4680. https://doi.org/10.1158/0008-5472.CAN-052909

Campbell DD, Parra MV, Duque C, Gallego N, Franco L, Tandon A, Hunemeier T, Bortolini C, Villegas A, Bedoya G, McCarthy MI, Price A, Reich D, Ruiz-Linares A (2012) Amerind ancestry, socioeconomic status and the genetics of type 2 diabetes in a Colombian population. PloS One 7: e33570. https://doi.org/10.1371/journal. pone.0033570

Carpino PA, Goodwin B (2010) Diabetes area participation analysis: a review of companies and targets described in the 2008-2010 patent literature. Expert Opin Therapeutic Patents 20: 1627-1651.https://doi. org/10.1517/13543776.2010.533171

Chehade JM, Mooradian AD (2000) A rational approach to drug therapy of type 2 diabetes mellitus. Drugs, 60(1): 95-113..

DeFronzo RA (2004) Pathogenesis of type 2 diabetes mellitus. Med Clinics North Am 88: 787-835. ix.https://doi.org/10.1016/j. mcna.2004.04.013

Gertow K, Sennblad B, Strawbridge RJ, Ohrvik J, Zabaneh D, Shah S, Veglia F, Fava C, Kavousi M, McLachlan S, Kivimäki M, Bolton JL, Folkersen L, Gigante B, Leander K, Vikström M, Larsson M, Silveira A, Deanfield J, Voight BF, Fontanillas P, Sabater-Lleal M, Colombo GI, Kumari M, Langenberg C, Wareham NJ, Uitterlinden UH, Gabrielsen AF-C, Nyyssönen K, Rauramaa R, Tuomainen T-P, Smit AJ, Giral P, Mannarino E, Robertson CM, Talmud PJ, Hedblad B, Hofman A, Erdmann J, Reilly MP, O'Donnell CJ, Farrall M, Clarke R, Grazia Franzosi M, Seedorf U, Syvänen A-C, Hansson GK, Eriksson P, Samani NJ, Watkins H, Price JF, Hingorani AD, Melander O, Witteman JCM, Baldassarre D, Tremoli E, de Faire U, Humphries SE, Hamsten A (2012) Identification of the BCAR1CFDP1-TMEM170A locus as a determinant of carotid intima-media thickness and coronary artery disease risk. Circulation Cardiovasc Genet 5: 656-665. https://doi.org/10.1161/CIRCGENETICS.112.963660

Harder MN, Ribel-Madsen R, Justesen JM, Sparso T, Andersson EA, Grarup N, Jorgensen T, Linneberg A, Hansen T, Pedersen O (2013) Type 2 diabetes risk alleles near BCAR1 and in ANK1 associate with decreased beta-cell function whereas risk alleles near ANKRD55 and GRB14 associate with decreased insulin sensitivity in the Danish Inter99 cohort. J Clinic Endocrinol Met 98: E801-E806. https://doi.org/10.1210/jc.2012-4169

Kanner SB, Reynolds AB, Parsons JT (1991) Tyrosine phosphorylation of a 120-kilodalton pp60src substrate upon epidermal growth factor and platelet-derived growth factor receptor stimulation and in polyomavirus middle-T-antigen-transformed cells. Mol Cell Biol 11: $713-720$

Keaton JM, Cooke Bailey JN, Palmer ND, Freedman BI, Langefeld CD, Ng MC, Bowden DW (2014) A comparison of type 2 diabetes risk allele load between African Americans and European Americans. Hum Genet 133: 1487-1495. https://doi.org/10.1007/s00439014-1486-5

Laakso M, Lehto S, Penttila I, Pyorala K (1993) Lipids and lipoproteins predicting coronary heart disease mortality and morbidity in patients with non-insulin-dependent diabetes. Circulation 88: 1421-1430

Maclay JD, McAllister DA, Macnee W (2007) Cardiovascular risk in chronic obstructive pulmonary disease. Respirology 12: 634-641. https://doi.org/10.1111/j.1440-1843.2007.01136.x

Manninen V, Tenkanen L, Koskinen P, Huttunen JK, Manttari M, Heinonen OP, Frick MH (1992) Joint effects of serum triglyceride and LDL cholesterol and HDL cholesterol concentrations on coro- 
nary heart disease risk in the Helsinki Heart Study. Implications for treatment. Circulation 85: 37-45

Matsuba R, Sakai K, Imamura M, Tanaka Y, Iwata M, Hirose H, Kaku K, Maegawa H, Watada H, Tobe K, Kashiwagi A, Kawamori R, Maeda S (2015) Replication study in a Japanese population to evaluate the association between $10 \mathrm{SNP}$ loci, identified in european genome-wide association studies, and type 2 diabetes. PloS One 10: e0126363. https://doi.org/10.1371/journal.pone.0126363

McCarthy MI, Zeggini E (2009) Genome-wide association studies in type 2 diabetes. Curr Diabetes Rep 9: 164-171

Morris AP, Voight BF, Teslovich TM, Ferreira T, Segre AV, Steinthorsdottir V, Strawbridge RJ, Khan H, Grallert H, Mahajan A, Prokopenko I, Kang HM, Dina C, Esko T, Fraser RM, Kanoni S, Kumar A, Lagou V, Langenberg C, Luan J, Lindgren CM, Müller-Nurasyid M, Pechlivanis S, Rayner NW, Scott LJ, Wiltshire S, Yengo L, Kinnunen L, Rossin EJ, Raychaudhuri S, Johnson AD, Dimas AS, Loos RJ, Vedantam S, Chen H, Florez JC, Fox C, Liu CT, Rybin D, Couper DJ, Kao WH, Li M, Cornelis MC, Kraft P, Sun Q, van Dam RM, Stringham HM, Chines PS, Fischer K, Fontanillas P, Holmen OL, Hunt SE, Jackson AU, Kong A, Lawrence R, Meyer J, Perry JR, Platou CG, Potter S, Rehnberg E, Robertson N, Sivapalaratnam S, Stančáková A, Stirrups K, Thorleifsson G, Tikkanen E, Wood AR, Almgren P, Atalay M, Benediktsson R, Bonnycastle LL, Burtt N, Carey J, Charpentier G, Crenshaw AT, Doney AS, Dorkhan M, Edkins S, Emilsson V, Eury E, Forsen T, Gertow K, Gigante B, Grant GB, Groves CJ, Guiducci C, Herder C, Hreidarsson AB, Hui J, James A, Jonsson A, Rathmann W, Klopp N, Kravic J, Krjutškov K, Langford C, Leander K, Lindholm E, Lobbens S, Männistö S, Mirza G, Mühleisen TW, Musk B, Parkin M, Rallidis L, Saramies J, Sennblad B, Shah S, Sigurðsson G, Silveira A, Steinbach G, Thorand B, Trakalo J, Veglia F, Wennauer R, Winckler W, Zabaneh D, Campbell H, van Duijn C, Uitterlinden AG, Hofman A, Sijbrands E, Abecasis GR, Owen KR, Zeggini E, Trip MD, Forouhi NG, Syvänen AC, Eriksson JG, Peltonen L, Nöthen MM, Balkau B, Palmer CN, Lyssenko V, Tuomi T, Isomaa B, Hunter DJ, Qi L; Wellcome Trust Case Control Consortium; Meta-Analyses of Glucose and Insulin-related traits Consortium (MAGIC) Investigators; Genetic Investigation of ANthropometric Traits (GIANT) Consortium; Asian Genetic Epidemiology Network-Type 2 Diabetes (AGEN-T2D) Consortium; South Asian Type 2 Diabetes (SAT2D) Consortium, Shuldiner AR, Roden M, Barroso I, Wilsgaard T, Beilby J, Hovingh K, Price JF, Wilson JF, Rauramaa R, Lakka TA, Lind L, Dedoussis G, Njølstad I, Pedersen NL, Khaw KT, Wareham NJ, Keinanen-Kiukaanniemi SM, Saaristo TE, Korpi-Hyövälti E, Saltevo J, Laakso M, Kuusisto J, Metspalu A, Collins FS, Mohlke KL, Bergman RN, Tuomilehto J, Boehm BO, Gieger C, Hveem K, Cauchi S, Froguel P, Baldassarre D, Tremoli E, Humphries SE, Saleheen D, Danesh J, Ingelsson E, Ripatti S, Salomaa V, Erbel R, Jöckel KH, Moebus S, Peters A, Illig T, de Faire U, Hamsten A, Morris AD, Donnelly PJ, Frayling TM, Hattersley AT, Boerwinkle E, Melander O, Kathiresan S, Nilsson PM, Deloukas P, Thorsteinsdottir U, Groop LC, Stefansson K, Hu F, Pankow JS, Dupuis J, Meigs JB, Altshuler D, Boehnke M, McCarthy MI; DIAbetes Genetics Replication And Meta-analysis (DIAGRAM) Consortium (2012) Large-scale association analysis provides insights into the genetic architecture and pathophysiology of type 2 diabetes. Nature Genet 44: 981-990. https://doi.org/10.1038/ng.2383

Pan C, Yang W, Jia W, Weng J, Tian H (2009) Management of Chinese patients with type 2 diabetes, 1998-2006: the Diabcare-China surveys. Curr Med Res Opin 25: 39-45. https://doi. org/10.1185/03007990802586079

Qi L, Cornelis MC, Kraft P, Stanya KJ, Linda Kao WH, Pankow JS, Dupuis J, Florez JC, Fox CS, Pare G, Qi Sun CJ, Girman CC, Lau- rie DB, Mirel TA, Manolio DI, Chasman E, Boerwinkle PM, Ridker DJ, Hunter JB, Meigs Ch-HL, Meta-Analysis of Glucose and Insulin-related traits Consortium (MAGIC), Diabetes Genetics Replication and Meta-analysis (DIAGRAM) Consortium, van Dam RM, Hu FB (2010) Genetic variants at 2q24 are associated with susceptibility to type 2 diabetes. Hum Mol Genet 19: 2706-2715. https://doi. org/10.1093/hmg/ddq156

Reynolds AB, Roesel DJ, Kanner SB, Parsons JT (1989) Transformation-specific tyrosine phosphorylation of a novel cellular protein in chicken cells expressing oncogenic variants of the avian cellular src gene. Mol Cell Biol 9: 629-638

Saltiel AR, Kahn CR (2001) Insulin signalling and the regulation of glucose and lipid metabolism. Nature 414: 799-806. https://doi. org/10.1038/414799a

Sanghera DK, Blackett PR (2012) Type 2 diabetes genetics: beyond GWAS. J Diabetes Metabolism 3. https://doi.org/10.4172/21556156.1000198

Shoelson SE, Lee J, Goldfine AB (2006) Inflammation and insulin resistance. J Clin Invest 116: 1793-1801. https://doi.org/10.1172/ JCI29069

't Hart LM, Fritsche A, Nijpels G, van Leeuwen N, Donnelly LA, Dekker JM, Alssema M, Fadista J, Carlotti F, Gjesing AP, Palmer CNA, van Haeften TW, Herzberg-Schäfer SA, Simonis-Bik AMC, Houwing-Duistermaat JJ, Helmer Q, Deelen J, Guigas B, Hansen T, Machicao F, Willemsen G, Heine RJ, Kramer MHH, Holst JJ, de Koning EJP, Häring H-U, Pedersen O, Groop L, de Geus EJC, Slagboom PE, Boomsma DI, Eekhoff EMW, Pearson ER, Diamant M (2013) The CTRB1/2 locus affects diabetes susceptibility and treatment via the incretin pathway. Diabetes 62: 3275-3281. https:// doi.org/10.2337/db13-0227.

Takai T, Nishita Y, Iguchi-Ariga SM, Ariga H (1994) Molecular cloning of MSSP-2, a c-myc gene single-strand binding protein: characterization of binding specificity and DNA replication activity. Nucleic Acids Res 22: 5576-5581

Tang DD (2009) p130 Crk-associated substrate (CAS) in vascular smooth muscle. J Cardiovascular Pharmacol Ther 14: 89-98. https:// doi.org/10.1177/1074248409333490

Tao X, Li J, Zhu X, Zhao B, Sun J, Ji L, Hu D, Pan C, Huang Y, Jiang S, Feng Q, Jiang C, on behalf of CCMR-3B STUDY Investigators (2016) Association between socioeconomic status and metabolic control and diabetes complications: a cross-sectional nationwide study in Chinese adults with type 2 diabetes mellitus. Cardiovascular Diabetol 15: 61. https://doi.org/10.1186/s12933-016-0376-7

Tikhmyanova N, Little JL, Golemis EA (2010) CAS proteins in normal and pathological cell growth control. Cell Mol Life Sci: CMLS 67: 1025-1048. https://doi.org/10.1007/s00018-009-0213-1

Wild S, Roglic G, Green A, Sicree R, King H (2004) Global prevalence of diabetes: estimates for the year 2000 and projections for 2030 . Diabetes Care 27: 1047-1053

Yang W, Lu J, Weng J, Jia W, Ji L, Xiao J, Shan Z, Liu J, Tian H, Ji Q, Zhu D, Ge J, Lin L, Chen L, Guo X, Zhao Z, Li Q, Zhou $Z$, Shan G, He J, for the China National Diabetes and Metabolic Disorders Study Group (2010) Prevalence of diabetes among men and women in China. New Eng J Med 362: 1090-1101. https://doi. org/10.1056/NEJMoa0908292

Zhu XW, Deng FY, Wu LF, Tang ZX, Lei SF (2015) Functional mechanisms for type 2 diabetes-associated genetic variants. J Diabetes Complications 29: 497-501. https://doi.org/10.1016/j.jdiacomp.2015.02.007 